\title{
Discussion on the Traditional Sports Teaching Methods in China
}

\section{Hu Qinghua}

Hubei University for Nationalities, Sports Institute, Enshi, Hubei, 445000

Keywords: Traditional National Sports, Teaching Methods

\begin{abstract}
The Chinese nation is a great nation. In this multi ethnic family, many excellent cultures have been accumulated and the traditional national sports are one of them. Different ethnic groups have different national traditional sports, which includes a nation's pursuit of life and a unique historical culture of a nation. At present, physical education in our country adopts the concept of modern physical education, which is relatively limited in teaching traditional ethnic sports, and there are many problems in the process of teaching. Carrying out the national traditional sports education is not only to help students enhance their physique, but also to enable students to accept traditional culture, feel the unique charm of national traditional sports, and better inherit and carry forward traditional sports. It plays a very important role in the inheritance and development of our national traditional sports, so as to promote the overall development of sports education in China.
\end{abstract}

\section{The Important Significance of the Application of Traditional Ethnic Sports Teaching Methods}

The traditional national sports teaching method is an innovative attempt for the reform of physical education, and it is also a kind of inheritance and development for Chinese traditional culture. It has a very important significance and a positive role in promoting.

\subsection{Traditional national sports teaching help to promote the reform of sports education}

Our country has many national cultures. Traditional sports have been inherited and developed from generation to generation, which is quite different from the unique charm of our national traditional sports. However, from the current physical education teaching, it has been using the modern sports teaching mode, too much emphasis on skills and physical training, and less infiltration of culture, so it is difficult for students to get interested. In addition to the heavy pressure of learning, students prefer to participate in some more relaxed and more interesting outdoor activities [1]. Therefore, integrating national traditional sports and modern sports and increasing the cultural connotation and interest of physical education will help to change the rigid teaching mode and guide students to participate in sports teaching activities, so that sports teaching can be more vigorous.

\subsection{The traditional national teaching method helps to improve the students' interest in learning}

National traditional sports are different from modern sports, though they are not very difficult skills, but after generations of inheritance and development, they have profound cultural connotations for traditional sports. At the same time, because the national traditional sports are people's activities in their life practice, they are relatively strong in mass and interest, but also have strong national characteristics [2]. They are more easily accepted by students, and are also consistent with their personality traits. The combination of traditional sports and modern sports teaching can not only help us improve students' interest in learning sports, but also more importantly, national traditional sports. Its rich historical connotation can also help students better understand sports, which is significant and far-reaching. 


\subsection{National traditional physical education helps to inherit and carry forward Chinese traditional culture}

China is a traditional ancient country with 5000 years of civilization. Many excellent cultures have been passed down and carried forward, including the traditional national sports. These sports are not only popular with people, but more importantly, it inherits the wisdom of the people of the Chinese people for thousands of years and the emotional elements of their love of life. The unique culture of China needs the inheritance and development of our generation [3]. Developing national traditional sports teaching mode can integrate traditional culture with physical education, and enable students to understand the unique charm of national traditional sports in the process of learning. In order to better understand Chinese excellent traditional culture, inherit Chinese excellent traditional culture and develop Chinese excellent traditional culture.

\section{The Basic Characteristics of the Teaching Mode of National Traditional Physical Education}

With the increasingly urgent desire for cultural pursuits and the profound connotation and unique charm of traditional culture, Chinese traditional excellent culture is once again popular. The traditional sports in China are inheriting the history. It is necessary for the school to develop traditional sports teaching. It is also in line with the fundamental need of the development of the times. In the past sports teaching process in China, modern sports teaching methods and methods are generally adopted. They lack enough attention to traditional sports, and even to a large extent, traditional sports are ignored [4-5]. These are not conducive to the development of national traditional sports, but also are not conducive to the inheritance and development of Chinese traditional culture. In the process of teaching, we should not only keep pace with the times, but also create the source. We should not forget our inherent culture while learning new knowledge and mastering new skills. We also have the obligation to make the national culture better inherit and carry forward. Therefore, the traditional national sport teaching is the trend of the times. However, there is a great difference between traditional sports and modern sports teaching. Besides, China has more than 50 nationalities and each nation has its own cultural and folk sports activities. Because of different regions, customs, culture and so on, it will bring difficulties to teaching. However, as long as we can understand the characteristics of national sports teaching, we can transmit skills to students.

\subsection{The teaching of national traditional sports is relatively easy}

The traditional national sports project comes from the folk, and comes from the heart of thousands of years. Many projects are created by people in the field of work or leisure time entertainment, the rules of the competition are relatively simple, it is relatively easy to not teach. In the course of teaching, without too much explanation, the project can be taught to the students, and the students can be quickly mastered. Therefore, in the national sports teaching, the main energy is to cultivate students' interest. They can tell students about their cultural background and historical allusions [6]. This allows the students to understand the story behind the sports events, thus triggering the enthusiasm of the students and better learning, which is also convenient for the teaching. Teachers can help students to improve the skills and skills of sports to master the basic tactics, and create conditions for the better development of national sports.

\subsection{Traditional ethnic sports are more likely to stimulate the enthusiasm of students' Participation}

The entertainment of national traditional sports is far greater than its athletics, which is determined by the background of the birth of national traditional sports. It is precisely because the national traditional sports come from the folk, and the collective wisdom comes from people's love for life and optimistic attitude towards life. Therefore, national traditional sports are often more interesting and interesting. Compared with modern sports, ethnic traditional sports seem more plain, but they can attract students to participate. This is the advantage of the traditional national sports 
teaching, but the traditional national sports are often simple, and the students can easily learn. Without some innovation, it is possible that some students will not be involved in learning because of their loss of interest [7-8]. Therefore, in the process of national traditional sports teaching, we should integrate more into the ideas and elements of modern sports teaching, while preserving interest, and at the same time, increase some competitiveness so that students can continue to love this sport.

\subsection{The organization of traditional national sports teaching activities is more simple and convenient}

Unlike modern sports, national traditional sports teaching is easy to organize competitions, and do not need too many devices and tools. This is due to the inherent characteristics of traditional national sports teaching. It is precisely because of this, the traditional national sports teaching can be carried out at any time, and it does not need to be held in any form. As long as students master certain skills and tactics, they can fight, and some activities can be individual confrontation or group confrontation. This creates conditions for our organization activities, and with the strong interest of national traditional sports, we can soon ignite the vitality of students. Let students gain happiness, friendship, knowledge and physical fitness through a simple game against them.

\section{The Teaching Methods of Traditional National Sports}

Although the traditional national sports project is relatively simple, it can be well realized both from teaching and learning. However, in order to better inherit and develop national traditional sports, a scientific teaching method is still needed to achieve better inheritance and development of traditional culture.

\subsection{To achieve multi point force around local characteristics}

Ethnic traditional sports come from different nationalities, different regions, different nationalities and different customs will derive different ethnic traditional sports. Based on this characteristic, we should adjust measures to local conditions in the process of developing national traditional sports teaching. Schools should focus on traditional sports with local characteristics and arrange them into teaching contents. First, it can make students easy to learn, so that the teaching work gets twice the result of twice the result [9]. As a local project, some students have mastered the basic skills and tactics, and teachers can only achieve the purpose of teaching only from the side tutoring. The two is to let students learn the local traditional sports and feel the traditional culture in their own areas. This can allow them to have a deeper understanding and understanding in their participation, and to fall in love with their own traditional culture. At the same time, according to the actual situation, we will arrange the traditional ethnic sports in other areas reasonably, so that students can feel the unique charm of traditional culture in different areas, step by step and make more efforts [10]. Constantly mobilize the initiative and enthusiasm of students in teaching activities. Through various forms of sports activities, it can relieve students' intense learning pressure and go outside to exercise.

\subsection{Pay attention to safety protection and protect the physical and mental health of students}

The interest of the traditional national sports is more interesting than that of competitive sports, but there is no sports risk. If it is not protected, it will cause the students to be injured. One is to step by step and not to eat a fat person at one time. Although exercise can help us to improve our health and relax our body and mind, high intensity and fierce or fierce sports may bring harm to students. Therefore, in the course of teaching, the teacher must put the safety protection in the first place and arrange the intensity of the movement reasonably. In some projects with strong antagonism, the students should be equipped with protective equipment to prevent sports injury. The physique of different people and different students is different. Teachers should fully understand the physical condition of each student, arrange sports in a targeted way, and not be able to organize scientifically according to individual differences according to the same standard. For example, students with 
good health can increase their exercise volume and help students improve better. For some relatively poor students, we should reduce their exercise volume and help them gradually enhance their physical fitness. Three is to do a complete set of facilities and outdoor sports will inevitably have a sports risk. Therefore, in the course of teaching, teachers should strengthen the safety education for students. Some unsafe behavior is exhorted, especially for some unstandardized technical movements that can easily cause sports injury. At the same time, we should pay attention to the establishment of safety facilities and safety measures to create a safe sports environment for students.

\subsection{Pay attention to interest and creativity and stimulate students' enthusiasm for learning}

Students should be the main body of teaching, not passive learning. We should encourage students to take the initiative to participate in it, and change passive teaching into active learning, so that we can better guarantee learning quality and learning effect. Therefore, in the development of national traditional sports teaching, the main energy should be put on the cultivation of students' interest. Let the students be able to enjoy sports activities, encourage them to participate actively, feel the happiness brought by sports, and feel the influence of traditional culture. To achieve this, we must start from two aspects: first, we must pay attention to interest; the traditional national sports itself has strong interest, which is the advantage of the national traditional sports. But because these traditional sports are relatively simple, it is possible for students to lose interest for a long time [11]. Therefore, in the process of teaching, we should highlight its interest, enable students to have fun, highlight the effect of entertainment, rather than impose too many skills and tactics. The two is to pay attention to innovation, and any good sports project will become tedious if it is not constant for a long time. Teachers should combine traditional sports with modern physical education and constantly innovate the forms and methods of traditional sports so that students can feel something different from time to time and maintain their enthusiasm for sports at all times.

\subsection{Integrating modern teaching ideas and paying attention to the all-round development of people}

The teaching of physical education should not be used as an appendage to the school teaching, and the voice of the students' quality education is becoming more and more high. Physical education should give full play to its role, integrate modern teaching ideas, pay attention to physical fitness and pay more attention to quality education. In the process of teaching, national traditional sports should put the awareness of cultivating sports in the first place, cultivate the enterprising spirit in the first place, and cultivate the spirit of unity and cooperation in the first place. Let the students in a happy atmosphere, feeling the movement to bring happiness; let the students in the constant self-challenge, feel the enterprising strength; let the students in cooperation with each other in the sense of unity, through subtle teaching methods, to achieve the comprehensive and coordinated development.

\subsection{Carry forward the traditional culture and inherit the national gem}

One of the important reasons for the inheritance of traditional sports is that the cultural background behind the traditional sports of every nation is supported. Only the power of culture can give it distinctive charm. Therefore, in the development of traditional national sports teaching, the heritage of culture should be regarded as an important one. At present, the phenomenon of our students being invaded by western culture is more serious. The students only know Spiderman and captain of the United States, but we don't know our own heroes like Qi Jiguang and Yue Fei [12]. After that, students' national pride will be reduced one by one. Our country has a very rich traditional culture, which needs to be better inherited and developed. We must carry forward traditional culture as an important part of students' ideological education. Through national traditional sports teaching, we transmit our culture to students, so that students can deeply recognize the gravity of Chinese culture and feel the broad and profound traditional culture, so as to fall in love with our culture and become the main force of inheriting Chinese culture. 


\section{Conclusion}

China is a traditional ancient country. In the past five thousand years, we have accumulated many wonderful culture and created many excellent traditional sports. These projects are our historical treasures, which need us to be passed on, and we need to be further promoted. Therefore, developing national traditional sports is of great significance. We need to continue to explore new ways and initiatives so that our national traditional sports will continue to show their unique charm in the succession of generations.

\section{References}

[1] Jiao Z, University W. Experimental Study on the Application of Group Dynamic Theory in Middle School Sports Teaching Methods Classroom Teaching[J]. Guide of Science \& Education, 2014.

[2] Feng J. Thinking About the Goal of Modern School Physical Education in our Country from the Overseas Sports Teaching Goal Setting[J]. Contemporary Sports Technology, 2016.

[3] D.C. Preciado-Martínez, E.M. Mancera-Soto, E.D. Hernández-Álvarez, et al. Effectiveness of sports teaching methods in the 40x40 program in overweight and obesity in school children[J]. Revista De La Facultad De Medicina Universidad Nacional De Colombia, 2016, 64(3):143-150.

[4] Qin L, Zhang S, Qin L, et al. Application of Outward Bound in Traditional Sports Teaching of Minority in China[C]// International Conference on Innovations in Economic Management and Social Science. 2017.

[5] Liu M. The Development of Traditional Sports Teaching in Primary and Secondary Schools in Guangxi[J]. Sport Science \& Technology, 2014.

[6] Liu C. Study on Sports Teaching Method and Practice in the Concept of Innovation Education[J]. Academic Journal of Shaolin \& Taiji, 2015.

[7] Hou N J. Study on Complementary of Multimedia Teaching and Traditional Teaching Methods in Physical Education Teaching[J]. Bulletin of Sport Science \& Technology, 2013.

[8] Tan H, Xia W. Study on Interactive Division Teaching Method in Sports Dance Compulsory Class of Physical Education[M]// Informatics and Management Science III. Springer London, 2013.

[9] Zhang Ji-chun, Yancheng teachers university. Methods of teaching children to swim for beginners[J]. Fujian Sports Science \& Technology, 2015.

[10] Li A, Long J, Tao G, et al. Research on the Inquiry Teaching Model of Men's Basketball Teaching in College Physical Education based on Network Information Technology[J]. International Journal of Smart Home, 2015, 9(10):169-178.

[11] Hong Xu. Application Research on Higher Vocational Teaching of volleyball game teaching method[J]. Journal of Qiqihar Junior Teachers College, 2015.

[12] Jansen A J. New Teaching Methods in Sports Engineering; How to Speed-up Learning While Having Fun! 话[J]. Procedia Engineering, 2015, 112:568-572. 